DOI 10. 18307/2022. 0212

(C) 2022 by Journal of Lake Sciences

\title{
白洋淀湿地不同植物群落区表层沉积物碳氮磷化学计量特征”
}

\author{
尹 德超 $^{1}$, 王雨山 ${ }^{1 * *}$, 祁晓凡 ${ }^{1,2}$, 安永会 ${ }^{1}$, 王旭清 ${ }^{1}$, 徐蓉桢 ${ }^{1}$ \\ (1: 中国地质调查局水文地质环境地质调查中心,保定 071051) \\ (2: 中国地质调查局地质环境监测院,北京 100081)
}

\begin{abstract}
摘 要: 白洋淀是雄安新区的核心生态功能区. 为探究白洋淀不同植物群落区表层沉积物碳 $(\mathrm{C})$ 氮 $(\mathrm{N})$ 磷 $(\mathrm{P})$ 化学计量 特征,采集了 96 组表层沉积物样品开展对比分析. 研究表明: 白洋淀湿地表层沉积物总有机碳 ( TOC) 含量均值为 39.64 $\mathrm{g} / \mathrm{kg}$, 范围为 $14.4 \sim 136.82 \mathrm{~g} / \mathrm{kg}$, 总氮 $(\mathrm{TN})$ 和总磷 ( TP ) 均值分别为 2.62 和 $0.75 \mathrm{~g} / \mathrm{kg}$, 范围分别为 $0.72 \sim 10.57$ 和 $0.46 \sim$ $1.38 \mathrm{~g} / \mathrm{kg}$; 不同植物群落区表层沉积物 C、N、P 化学计量特征存在显著差异, 挺水植物分布区表层沉积物 TOC 和 TN 含量 高于其他区, 水田区沉积物 TP 含量最高; 表层沉积物 $\mathrm{C}: \mathrm{N}: \mathrm{P}$ 比例平均值为 $141: 8: 1, \mathrm{C}: \mathrm{N}$ 比值相对稳定, $\mathrm{C}: \mathrm{P}$ 和 $\mathrm{N}: \mathrm{P}$ 比 值空间分异性较大; 不同水生植物群落区沉积物 $C 、 N 、 P$ 化学计量特征存在差异, 挺水植物区沉积物 $C: P$ 和 $N: P$ 比值显 著高于其他各分区, 沉水植物区表层沉积物 $\mathrm{C}: \mathrm{N}$ 最大, 挺水植物区和沉水植物区 $\mathrm{C}: \mathrm{N}: \mathrm{P}$ 比例平均值分别为 $222: 13: 1$ 和 $129: 6.5: 1$; 白洋淀表层沉积物 C、N、P 化学计量特征受植物群落生物量、磷氮磷化学计量特征、枯落物分解速率以及人类 活动等多个因素影响; 与我国东部主要湖泊相比, 白洋淀表层沉积物 C、N、P 含量均处于较高水平, 建议在水生植物生长 末期收割打捞运出淀外,减少淀内 $N 、 P$ 营养盐累积,减缓白洋淀富营养化和沼泽化进程.
\end{abstract}

关键词: 白洋淀;底泥;碳氮磷;营养元素;化学计量学;分布特征

\section{Stoichiometric characteristics of carbon, nitrogen and phosphorus in surface sediments of different plant communities in Lake Baiyangdian wetland*}

\author{
Yin Dechao ${ }^{1}$, Wang Yushan ${ }^{1 * *}$, Qi Xiaofan ${ }^{1,2}$, An Yonghui ${ }^{1}$, Wang Xuqing ${ }^{1} \&$ Xu Rongzhen ${ }^{1}$ \\ (1: Center For Hydrogeology and Environmental Geology, CGS, Baoding 071051, P.R.China) \\ (2: China Institute of Geo-Environmental Monitoring, CGS, Beijing 100081, P.R.China)
}

Abstract: Lake Baiyangdian is the main ecological function area of Xiong'an New Area. To explore the stoichiometric characteris-
tics of carbon, nitrogen and phosphorus in surface sediments of different plant communities in Lake Baiyangdian, 96 samples of
surface sediment were collected for comparative analysis. Results showed that the average total organic carbon ( TOC) contents of
the surface sediments were $39.64 \mathrm{~g} / \mathrm{kg}$, ranging from 14.4 to $136.82 \mathrm{~g} / \mathrm{kg}$, while the average total nitrogen $(\mathrm{TN})$ and total phos-
phorus ( TP) contents were 2.62 and $0.75 \mathrm{~g} / \mathrm{kg}$, ranging from 0.72 to 10.57 and 0.46 to $1.38 \mathrm{~g} / \mathrm{kg}$, respectively. There were sig-
nificant differences in carbon and phosphorus stoichiometric characteristics of surface sediments in different plant community re-
gions. TOC and TN contents in surface sediment of emerged aquatic plant areas were higher than those in other areas, and TP con-
tents in surface sediment of paddy fields were the highest. The mean value of the $\mathrm{C}: \mathrm{N}: \mathrm{P}$ ratio in surface sediments was $141: 8: 1$,
the $\mathrm{C}: \mathrm{N}$ ratio was relatively stable, and the $\mathrm{C}: \mathrm{P}$ and $\mathrm{N}: \mathrm{P}$ ratios were highly variable. There were significant differences in carbon,
nitrogen and phosphorus stoichiometry in sediments of different aquatic plant communities. The ratios of $\mathrm{C}: \mathrm{P}$ and $\mathrm{N}: \mathrm{P}$ in surface
sediments of emerged aquatic plant areas were significantly higher than those of other regions. The mean $\mathrm{C}: \mathrm{N}: \mathrm{P}$ ratios of emerged
aquatic plant area and submerged plants area were $222: 13: 1$ and $129: 6.5: 1$, respectively. The stoichiometric characteristics of
carbon, nitrogen and phosphorus in surface sediments of Lake Baiyangdian were affected by many factors, such as plant community
biomass, stoichiometric characteristics, decomposition rate and human activities. Compared with the main lakes in eastern China,
the contents of carbon, nitrogen and phosphorus in the surface sediments of Lake Baiyangdian were at a higher level. It is suggested

* 2021-06-15 收稿; 2021-08-30 收修改稿.

中国地质调查局白洋淀地区生态地质调查项目 ( DD20190300) 资助.

** 通信作者; E-mail: wangyushan@ mail.cgs.gov.cn. 
to harvest, salvage and transport the aquatic plants out of the lake at the end of the growth period to reduce the accumulation of nitrogen and phosphorus nutrients in the lake and slow down the process of eutrophication and swamping of Lake Baiyangdian.

Keywords: Lake Baiyangdian; surface sediments; carbon, nitrogen and phosphorus; nutrient elements; stoichiometric; distribution characteristics

白洋淀位于河北省中部, 是华北地区最具代表性的湖泊湿地,发挥着调节气候、蓄水兴利、旅游景观等 多种重要生态功能 ${ }^{[1]}$. 近半个世纪以来, 受气候变化和人类活动共同影响, 白洋淀面临水源不足、湿地萎缩、 水体污染、泥沙淤积等生态环境问题 ${ }^{[2-3]} .2017$ 年, 中共中央、国务院决定成立河北雄安新区, 白洋淀作为其 核心生态功能区, 其生态环境状况受到各界的广泛关注. 表层沉积物是湖泊湿地的重要组成部分, 是 $C 、 N 、 P$ 营养元素的重要蓄积库, 在湖泊湿地生物地球化学元素循环中扮演着十分重要的角色 ${ }^{[4-9]}$, 查明表层沉积物 $C 、 N 、 P$ 赋存规律对白洋淀生态保护与修复具有重要意义.

化学计量学作为一种新的生态学研究工具已经被广泛应用于生物个体、群落以及生态系统的各个层 次 ${ }^{[10-11]}$, 为研究 $C 、 N 、 P$ 等元素的生物地球化学循环提供了一种新思路 ${ }^{[12-14]}$. 近年来研究表明, 全球土壤具 有相对稳定的 $\mathrm{C}: \mathrm{N}: \mathrm{P}$ 比例 (摩尔比, 下同), 为 $60: 7: 1^{[15]}$, 我国表层 $0 \sim 10 \mathrm{~cm}$ 土壤 $\mathrm{C}: \mathrm{N}: \mathrm{P}$ 为 $134: 9: 1^{[16]}$, 湿 地土壤的 $\mathrm{C}: \mathrm{N}: \mathrm{P}$ 比例平均值为 $245: 13.6: 1^{[17]}$, 植被、气候、水文情势等因素均会影响沉积物的 $\mathrm{C} 、 \mathrm{~N} 、 \mathrm{P}$ 化学 计量特征. 例如, Hu 等 ${ }^{[18]}$ 研究东洞庭湖地区 3 种挺水植物覆盖下沉积物的 C、N、P 计量化学特征, Zhang 等 ${ }^{[19]}$ 研究了三江平原沙東和毛果苔草湿地沉积物的 C、N、P 计量化学特征等, 均表明植物群落会影响湿地 表层沉积物 $C 、 N 、 P$ 化学计量特征.

已有学者对白洋淀表层沉积物 $\mathrm{N} 、 \mathrm{P}$ 的内源释放、垂向分布、污染评价等开展研究 ${ }^{[20-23]}$, 研究结果表明, 白洋淀表层沉积物 $N 、 P$ 污染负荷较高, 内源 $N 、 P$ 负荷已成为加剧白洋淀富营养化的重要污染源, 严重威胁 到白洋淀水环境质量. 但是, 目前对白洋淀表层沉积物碳氮磷化学计量特征及其影响因素的研究较少. 白洋 淀水生植物类型多样, 不同类型植物群落 $\mathrm{C} 、 \mathrm{~N} 、 \mathrm{P}$ 化学计量特征存在差异 ${ }^{[24-27]}$, 而植被枯落物又是沉积物 $\mathrm{C} 、$ $\mathrm{N} 、 \mathrm{P}$ 的主要来源. 根据水文资料, 1997 年至今白洋淀年均人淀水量 $\left(2.4 \times 10^{8} \mathrm{~m}^{3}\right)$ 仅为 $1951-1965$ 年平均人 淀水量 $\left(21.7 \times 10^{8} \mathrm{~m}^{3}\right)$ 的 $11 \%$, 来水量少且淀内围埝纵横, 阻碍了地表水对表层沉积物的搬运堆积作用. 由 此推测, 白洋淀表层沉积物 $C 、 N 、 P$ 化学计量特征主要受植物群落类型影响, 不同植物群落区表层沉积物 $C 、$ $\mathrm{N} 、 \mathrm{P}$ 含量应存在显著差异.

基于此,笔者在白洋淀不同水生植物群落区采集多个表层沉积物样品, 试图回答 2 个科学问题: (1) 白 洋淀表层沉积物 $C 、 N 、 P$ 是否符合我国土壤 $C 、 N 、 P$ 化学计量特征, 是否存在相对稳定的比值? (2) 白洋淀表 层沉积物 $C 、 N 、 P$ 化学计量特征是否与植被类型有关, 主要受哪些因素影响? 希望研究结果能初步揭示白洋 淀表层沉积物 $C 、 N 、 P$ 分布规律, 为了解白洋淀 $C 、 N 、 P$ 生物地球化学循环过程提供科学依据.

\section{1 材料与方法}

\section{1 研究区概况}

白洋淀 ( $38^{\circ} 43^{\prime} \sim 40^{\circ} 0^{\prime} \mathrm{N}, 115^{\circ} 45^{\prime} \sim 116^{\circ} 7^{\prime} \mathrm{E}$ ) 地处太行山东麓滹沱河冲洪积平原和永定河冲洪积平原夹 持的低洼地带, 面积 $360 \mathrm{~km}^{2}$, 是河北平原最大的湖泊湿地. 人淀河流有 8 条, 自南向北分别为潴龙河、孝义 河、唐河、府河、漕河、瀑河、萍河及白沟引河 ${ }^{[1]}$, 东侧束林庄水利枢纽为出水口, 经赵王新河汇人大清河, 东 流人海. 白洋淀 143 个淀泊星罗棋布 ${ }^{[28]}$, 主要淀泊包括藻苲淀、烧车淀、小白洋淀、捞王淀、池鱼淀和泛鱼 淀等.

白洋淀生态环境类型多样, 水生植物主要包括挺水植物、浮水植物和沉水植物, 其中浮水植物种类和数 量较少 ${ }^{[29]}$. 按照湿地植物群落类型和生态功能差异, 分为挺水植物群落区、沉水植物群落区、水田区、航道 区 4 种类型. 其中,挺水植物区水深多为 $0.5 \sim 2 \mathrm{~m}$, 芦苇 (Phragmites australis)、香蒲 (Typha orientalis Presl)、 荷 (Nelumbo nucifera) 等挺水植物为优势物种, 兼有菹草 (Potamogeton crispus)、金鱼藻 (Ceratophyllum demersum L. )、篦齿眼子菜 (Stuckenia pectinata) 等沉水植物; 沉水植物区水面开阔, 水深多 $>2 \mathrm{~m}$, 以䓚草、金鱼 藻、篦齿眼子菜等沉水植物为主; 航道位于围埝或台田之间, 沟通连接各淀泊, 是淀内主要行水通道, 且受往 
来船只影响, 水动力较强, 植物类型主要为沉水植物; 水田分布于淀区周边, 四周围埝圈闭, 主要为人工藕 田,局部分布有少量稻田.

\section{2 样品采集及测试}

2020 年 4-6 月,在白洋淀采集表层沉积物样品 96 组,采样深度 $10 \mathrm{~cm}$, 采样设备为 Corer $60 \mathrm{~mm}$ 柱状采 泥器, 每组样品为 $20 \mathrm{~m} \times 20 \mathrm{~m}$ 范围内的 4 次取样混合样. 表层沉积物样品采集后放人自封袋中, 置于保温箱 中冷藏. 表层沉积物样品采集的同时, 调查记录取样点周边优势植物类型等环境信息. 根据统计, 挺水植物 区、沉水植物区、水田区和航道内采集样品分别为 $22 、 40 、 11 、 23$ 组. 取样点分布及各取样点所处植物群落类 型如图 1 所示.

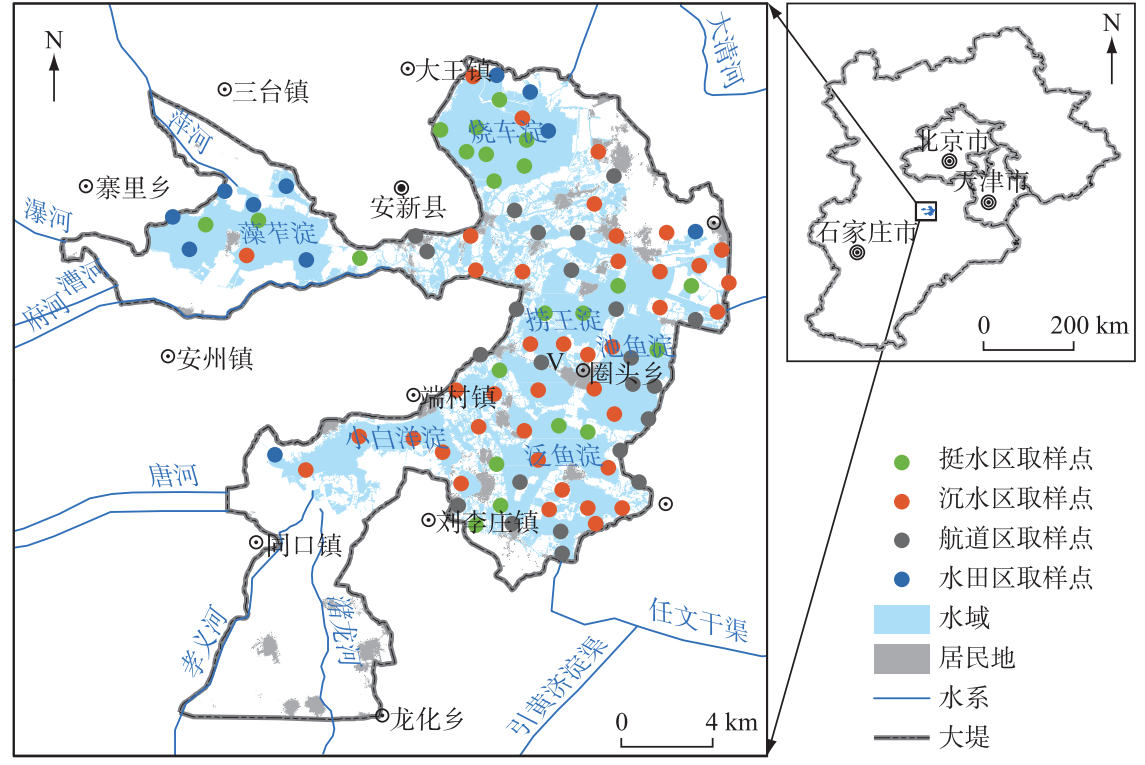

图 1 白洋淀表层沉积物取样点分布

Fig. 1 Distribution of sampling sites in surface sediments in Lake Baiyangdian

样品测试工作由河北省地质实验测试中心实验室完成, 测试项目包括总有机碳 (TOC)、总氮 ( TN)、总 磷 $(T P)$ 及其他组分, 其中 TOC 含量测定采用高频红外碳硫仪 ${ }^{[30]}, \mathrm{TN}$ 含量测定采用凯氏自动定氮仪 ${ }^{[31]}$, TP 含量测定采用 X 苂光光谱仪 ${ }^{[32]}$.

\section{3 数据处理及图件编制}

采用 SPSS 19.0 进行测试数据处理及统计分析: 利用描述统计功能对样品测试结果进行均值、极大值、 极小值、标准差、变异系数统计; 采用相关分析功能对 $\mathrm{C} 、 \mathrm{~N} 、 \mathrm{P}$ 含量及元素比值等变量进行相关性分析; 利用 单因素方差分析 (One-way ANOVA)、LSD 多重比较功能对比不同植被环境区表层沉积物 C、N、P 含量及比 值差异.

采用 ArcGIS 10.5 软件绘制采样点分布图及白洋淀表层沉积物 C、N、P 含量分布图, 采用 Excel 2016 和 Origin 8.5 绘制不同植物群落区表层沉积物碳氮磷含量对比直方图.

\section{2 结果}

\section{1 白洋淀表层沉积物 C、N、P 化学计量特征}

白洋淀表层沉积物 TOC 含量为 $14.4 \sim 136.82 \mathrm{~g} / \mathrm{kg}$, 均值为 $39.64 \mathrm{~g} / \mathrm{kg}$, 变异系数为 $51.50 \%$. TOC 含量大 于 $75 \mathrm{~g} / \mathrm{kg}$ 的取样点主要分布于北部烧车淀, 个别零散分布于捞王淀、池鱼淀和泛鱼淀. 藻苲淀、小白洋淀及 泛鱼淀取样点 TOC 含量小于 $50 \mathrm{~g} / \mathrm{kg}$. 表层沉积物 TN 含量为 $0.72 \sim 10.57 \mathrm{~g} / \mathrm{kg}$, 均值为 $2.62 \mathrm{~g} / \mathrm{kg}$, 变异系数 
为 $56.53 \%$ (表 1, 图 2). 沉积物 TN 含量分布特征与 TOC 含量分布有一定的相似性, 含量大于 $4.0 \mathrm{~g} / \mathrm{kg}$ 的取 样点主要分布于烧车淀, 其他个别零星分布于捞王淀、池鱼淀和泛鱼淀. 藻苲淀、小白洋淀及泛鱼淀沉积物 $\mathrm{TN}$ 含量小于 $3 \mathrm{~g} / \mathrm{kg}$. 表层沉积物 TP 含量为 $0.46 \sim 1.38 \mathrm{~g} / \mathrm{kg}$, 均值为 $0.75 \mathrm{~g} / \mathrm{kg}$, 变异系数为 $22.47 \%$. 沉积物 TP 含量分布与 TOC 和 TN 分布存在较大差异, TP 含量大于 $0.9 \mathrm{~g} / \mathrm{kg}$ 的采样点主要分布于藻苲淀西部、安新 县城南部和东部以及泛鱼淀南部等淀区. 表层沉积物 TOC、TN 和 TP 含量变异系数由大到小表现为 TN> TOC $>$ TP , 表明白洋淀表层沉积物 TP 含量在空间分布上比 TN 和 TOC 更为均一.

表层沉积物 $\mathrm{C}: \mathrm{N}$ 比值为11.35 35.31, 平均值为 18.73 , 高值点主要分布于东部東林庄、池鱼淀、泛鱼淀 等淀区. $\mathrm{C}: \mathrm{P}$ 比值为50.31 482.63, 平均值为 141.00 , 高值点主要分布于烧车淀、捞王淀、池鱼淀及泛鱼淀北 部等淀区. $N: P$ 比值为 $2.60 \sim 20.55$, 平均值为 7.79, 高值点分布区域与 $C: P$ 比值相近. $C: N 、 C: P$ 和 $N: P$ 比值 变异系数从大到小表现为 $\mathrm{C}: \mathrm{P}(56.0 \%)>\mathrm{N}: \mathrm{P}(53.2 \%)>\mathrm{C}: \mathrm{N}(25.6 \%)$, 表明白洋淀表层沉积物 $\mathrm{C}: \mathrm{N}$ 比值空 间分布相对稳定, $\mathrm{C}: \mathrm{P}$ 和 $\mathrm{N}: \mathrm{P}$ 比值空间异质性较大.

表 1 白洋淀及我国东部主要湖泊表层沉积物 $\mathrm{C} 、 \mathrm{~N}$ 、P 化学计量特征

Tab.1 Stoichiometric characteristics of C, N and P in surface sediments of Lake Baiyangdian and the main lakes in eastern China

\begin{tabular}{ccccccccc}
\hline \multirow{2}{*}{ 地区 } & 指标 & $\begin{array}{c}\mathrm{TOC} / \\
(\mathrm{g} / \mathrm{kg})\end{array}$ & $\begin{array}{c}\mathrm{TN} / \\
(\mathrm{g} / \mathrm{kg})\end{array}$ & $\begin{array}{c}\mathrm{TP} / \\
(\mathrm{g} / \mathrm{kg})\end{array}$ & $\mathrm{C}: \mathrm{N}$ & $\mathrm{C}: \mathrm{P}$ & $\mathrm{N}: \mathrm{P}$ & 文献来源 \\
\hline \multirow{2}{*}{ 白洋淀 } & 极小值 & 14.40 & 0.72 & 0.46 & 11.35 & 50.31 & 2.60 & 本研究 \\
& 极大值 & 136.82 & 10.57 & 1.38 & 35.31 & 482.63 & 20.55 & 本研究 \\
& 平均值 & 39.64 & 2.62 & 0.75 & 18.73 & 141.00 & 7.79 & 本研究 \\
& 标准差 & 20.41 & 1.48 & 0.17 & 4.80 & 79.03 & 4.15 & 本研究 \\
& 变异系数/\% & 51.50 & 56.50 & 22.50 & 25.60 & 56.00 & 53.20 & 本研究 \\
白洋淀 & 平均值 & 26.05 & 2.52 & 0.65 & 12.55 & 105.53 & 8.66 & 文献 [33] \\
& 平均值 & - & 2.38 & 0.61 & - & - & 8.64 & 文献 [20] \\
衡水湖 & 平均值 & 93.23 & 1.85 & 1.02 & 58.79 & 236.11 & 4.02 & 文献 [34] \\
洪泽湖 & 平均值 & 8.02 & 1.02 & 0.58 & 9.17 & 35.71 & 3.89 & 文献 [35] \\
太湖流域 & 平均值 & 10.47 & 1.35 & 0.49 & 9.05 & 55.64 & 6.15 & 文献 [36] \\
鄱阳湖 & 平均值 & - & 1.22 & 0.51 & - & - & 5.30 & 文献 [37] \\
洞庭湖 & 平均值 & 13.26 & 1.05 & 0.24 & 14.79 & 141.55 & 9.57 & 文献 [38] \\
长江中下游湖泊 & 平均值 & 20.26 & 2.03 & 0.56 & 11.64 & 93.46 & 8.03 & 文献[39] \\
\hline
\end{tabular}

Pearson 相关性分析结果表明 (表 2), 表层沉积物 TN 含量与 TP、TOC 和 $\mathrm{N}: \mathrm{P}$ 比值均呈显著正相关 $(P<$ $0.01)$, 与 $\mathrm{C}: \mathrm{N}$ 比值呈显著负相关 $(P<0.01)$; TP 含量与 $\mathrm{C}: \mathrm{P}$ 比值呈显著负相关 $(P<0.01)$, 与 $\mathrm{TOC}$ 和 $\mathrm{N}: \mathrm{P}$ 比 值没有相关性 $(P>0.05)$; TOC 含量与 $\mathrm{C}: \mathrm{P}$ 比值呈显著正相关 $(P<0.01)$, 与 $\mathrm{C}: \mathrm{N}$ 比值没有相关性 $(P>0.05)$. 由此可见,白洋淀表层沉积物 TN 含量变异对 $\mathrm{C} 、 \mathrm{~N} 、 \mathrm{P}$ 比值变化起主导作用.

表 2 白洋淀表层沉积物 C、N、P 含量及比值间的相关性分析

Tab.2 Correlation between contents and ratios of C, N and P in surface sediments of Lake Baiyangdian

\begin{tabular}{cccccc}
\hline 指标 & TOC & TN & TP & $\mathrm{C}: \mathrm{N}$ & $\mathrm{C}: \mathrm{P}$ \\
\hline TOC & & & & & \\
TN & $0.913^{* *}$ & & & & \\
TP & 0.079 & $0.307^{* *}$ & & & \\
C $: \mathrm{N}$ & -0.082 & $-0.405^{* *}$ & $-0.472^{* *}$ & & \\
$\mathrm{C}: \mathrm{P}$ & $0.893^{* *}$ & $0.691^{* *}$ & $-0.301^{* *}$ & 0.110 & \\
$\mathrm{~N}: \mathrm{P}$ & $0.917^{* *}$ & $0.885^{* *}$ & -0.106 & $-0.249^{*}$ & $0.905^{* *}$ \\
\hline
\end{tabular}

** 表示在 0.01 水平 $($ 双侧 $)$ 上显著相关; * 表示在 0.05 水平 $($ 双侧 $)$ 上显著相关. 

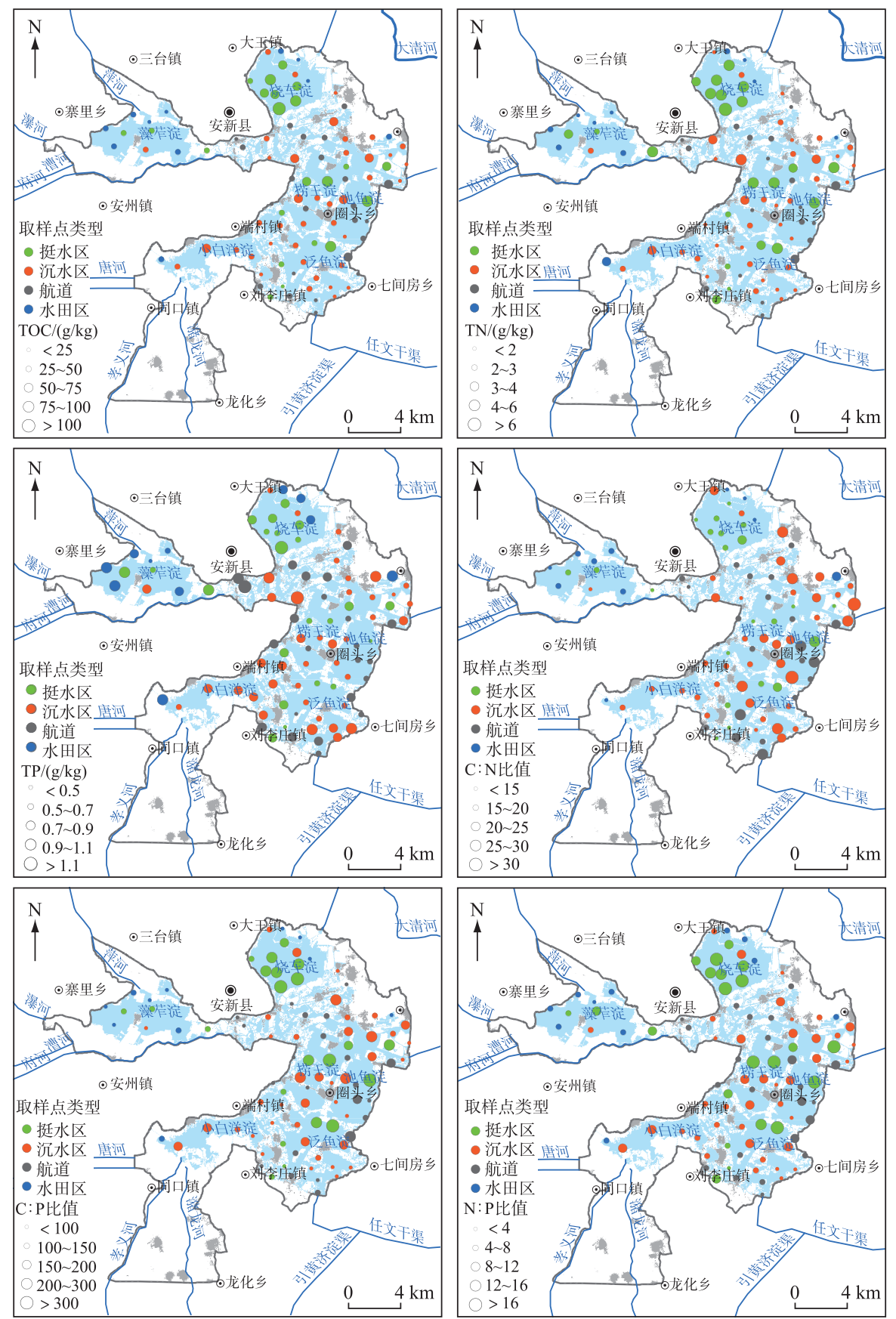

图 2 白洋淀表层沉积物 $\mathrm{C} 、 \mathrm{~N} 、 \mathrm{P}$ 含量及比值分布

Fig.2 Distribution of C, N and P contents and their ratios in surface sediments of Lake Baiyangdian

本次研究表层沉积物氮、磷含量与杜奕衡等 ${ }^{[20]} 2017$ 年取样测试结果基本一致,表明近 3 年白洋淀表层 沉积物氮磷含量基本稳定. 与张国锋等 ${ }^{[33]} 1995$ 年表层沉积物 C、N、P 研究成果相比, 白洋淀表层沉积物 TOC 含量有明显升高, TN 和 TP 含量则略有升高; 受 TOC 含量明显升高影响, C:N 和 C:P 比值显著上升, $\mathrm{N}: \mathrm{P}$ 比值则略有下降. 与我国东部主要湖泊表层沉积物 $\mathrm{C} 、 \mathrm{~N} 、 \mathrm{P}$ 平均含量 ${ }^{[34-39]}$ 相比, 白洋淀表层沉积物 $\mathrm{C} 、$ $\mathrm{N} 、 \mathrm{P}$ 含量均处于较高水平, $\mathrm{TN}$ 含量在我国东部主要湖泊最高, TOC 和 TP 含量仅低于衡水湖. 


\section{2 不同植物群落区表层沉积物 C、N、P 化学计量特征}

按照取样点植物群落类型, 统计表层沉积物 $C 、 N 、 P$ 化学计量特征(表 3). 单因素方差分析 (One-way ANOVA) 结果显示, 不同植物群落区 $\mathrm{TN} 、 \mathrm{TOC} 、 \mathrm{C}: \mathrm{N} 、 \mathrm{C}: \mathrm{P} 、 \mathrm{~N}: \mathrm{P}$ 存在显著差异 $(P<0.01)$, TP 含量在各分区之 间不存在显著差异 $(P>0.05)$. LSD 多重比较结果显示, 挺水植物群落区表层沉积物 TOC 含量显著高于其他 各区 $(P<0.01)$, 沉水植物区、航道区、水田区 TOC 含量无显著性差异 $(P>0.05)$. 挺水植物区 TN 含量均值为 $61.63 \mathrm{~g} / \mathrm{kg}$, 沉水植物区、航道区、水田区表层沉积物 TN 均值分别为 $35.39 、 31.01$ 和 $29.18 \mathrm{~g} / \mathrm{kg}$. 各植物类型 区表层沉积物 TN 含量特征与 TOC 相近, 挺水植物区显著高于其他各区 $(P<0.01)$, 沉水植物区、航道区、水 田区间 TN 含量无显著性差异 $(P>0.05)$. 挺水植物区表层沉积物 TN 含量均值为 $4.38 \mathrm{~g} / \mathrm{kg}$, 沉水植物区、航 道区、水田区 TN 含量均值分别为 $2.13 、 2.03$ 和 $2.13 \mathrm{~g} / \mathrm{kg}$. 挺水植物区、沉水植物区、航道区、水田区 4 种分区 表层沉积物 TP 含量不存在显著差异, 水田区表层沉积物 TP 含量均值略高 $(0.85 \mathrm{~g} / \mathrm{kg})$, 其次为航道区 $(0.76$ $\mathrm{g} / \mathrm{kg})$ 和挺水植物区 $(0.75 \mathrm{~g} / \mathrm{kg})$, 沉水植物群落区 TP 含量均值最低 $(0.73 \mathrm{~g} / \mathrm{kg})$.

表 3 白洋淀不同植物群落区沉积物 $C 、 N 、 P$ 化学计量特征

Tab.3 Stoichiometric characteristics of C, N and P in surface sediments of different plant community areas in Lake Baiyangdian

\begin{tabular}{|c|c|c|c|c|c|c|}
\hline 指标 & 环境 & 极小值 & 极大值 & 均值 & 标准差 & 变异系数 $/ \%$ \\
\hline \multirow[t]{4}{*}{$\mathrm{TOC} /(\mathrm{g} / \mathrm{kg})$} & 挺水区 & 14.40 & 136.82 & 61.63 & 26.88 & 43.62 \\
\hline & 沉水区 & 19.00 & 69.60 & 35.39 & 13.96 & 39.44 \\
\hline & 航道区 & 15.00 & 57.50 & 31.01 & 10.21 & 32.93 \\
\hline & 水田区 & 17.00 & 41.60 & 29.18 & 7.91 & 27.11 \\
\hline \multirow[t]{4}{*}{$\mathrm{TN} /(\mathrm{g} / \mathrm{kg})$} & 挺水区 & 1.37 & 10.57 & 4.38 & 1.78 & 40.69 \\
\hline & 沉水区 & 0.72 & 5.76 & 2.13 & 1.01 & 47.57 \\
\hline & 航道区 & 0.77 & 3.70 & 2.03 & 0.73 & 36.11 \\
\hline & 水田区 & 1.03 & 3.52 & 2.13 & 0.66 & 30.96 \\
\hline \multirow[t]{4}{*}{$\mathrm{TP} /(\mathrm{g} / \mathrm{kg})$} & 挺水区 & 0.46 & 1.14 & 0.75 & 0.18 & 24.09 \\
\hline & 沉水区 & 0.51 & 1.38 & 0.73 & 0.16 & 22.15 \\
\hline & 航道区 & 0.53 & 1.38 & 0.76 & 0.18 & 24.16 \\
\hline & 水田区 & 0.59 & 1.03 & 0.85 & 0.14 & 16.91 \\
\hline \multirow[t]{4}{*}{$\mathrm{C}: \mathrm{N}$} & 挺水区 & 11.35 & 26.59 & 16.39 & 3.79 & 23.13 \\
\hline & 沉水区 & 12.26 & 35.31 & 20.66 & 4.98 & 24.12 \\
\hline & 航道区 & 11.82 & 28.84 & 18.71 & 4.85 & 25.90 \\
\hline & 水田区 & 11.49 & 21.33 & 16.46 & 3.13 & 18.99 \\
\hline \multirow[t]{4}{*}{$\mathrm{C}: \mathrm{P}$} & 挺水区 & 81.53 & 482.63 & 222.19 & 108.83 & 48.98 \\
\hline & 沉水区 & 58.56 & 259.83 & 128.79 & 52.90 & 41.08 \\
\hline & 航道区 & 50.31 & 204.49 & 109.71 & 39.77 & 36.25 \\
\hline & 水田区 & 65.40 & 125.43 & 88.47 & 17.60 & 19.89 \\
\hline \multirow[t]{4}{*}{$N: P$} & 挺水区 & 6.66 & 20.55 & 13.11 & 4.43 & 33.80 \\
\hline & 沉水区 & 2.60 & 11.85 & 6.52 & 2.78 & 42.64 \\
\hline & 航道区 & 2.90 & 11.29 & 6.02 & 2.19 & 36.31 \\
\hline & 水田区 & 3.88 & 7.56 & 5.47 & 1.08 & 19.78 \\
\hline
\end{tabular}

沉水植物群落区表层沉积物 $\mathrm{C}: \mathrm{N}$ 比值最大, 均值为 19.35 , 显著高于挺水植物区 (16.42) 和水田区 (16.46), 与航道区沉积物 $\mathrm{C}: \mathrm{N}$ 比值 (18.71) 无明显差异. 挺水植物群落区表层沉积物 $\mathrm{C}: \mathrm{P}$ 比值显著高于其 他各分区 $(P<0.01)$, 均值为 212.41 , 沉水植物区、航道区、水田区表层沉积物 $\mathrm{C}: \mathrm{P}$ 比值无显著差异 $(P>$ $0.05)$, 均值分别为 $125.15 、 109.71$ 和 88.47. 表层沉积物 $\mathrm{N}: \mathrm{P}$ 值分布特征与 $\mathrm{C}: \mathrm{P}$ 比值相近, 挺水植物区表层 沉积物 $\mathrm{N}: \mathrm{P}$ 比值显著高于其他各分区 $(P<0.01)$, 均值为 12.93 , 沉水植物区、航道区、水田区 $\mathrm{N}: \mathrm{P}$ 比值无显 著差异 $(P>0.05)$, 均值分别为 6.47、6.02 和 5.47(图 3). 

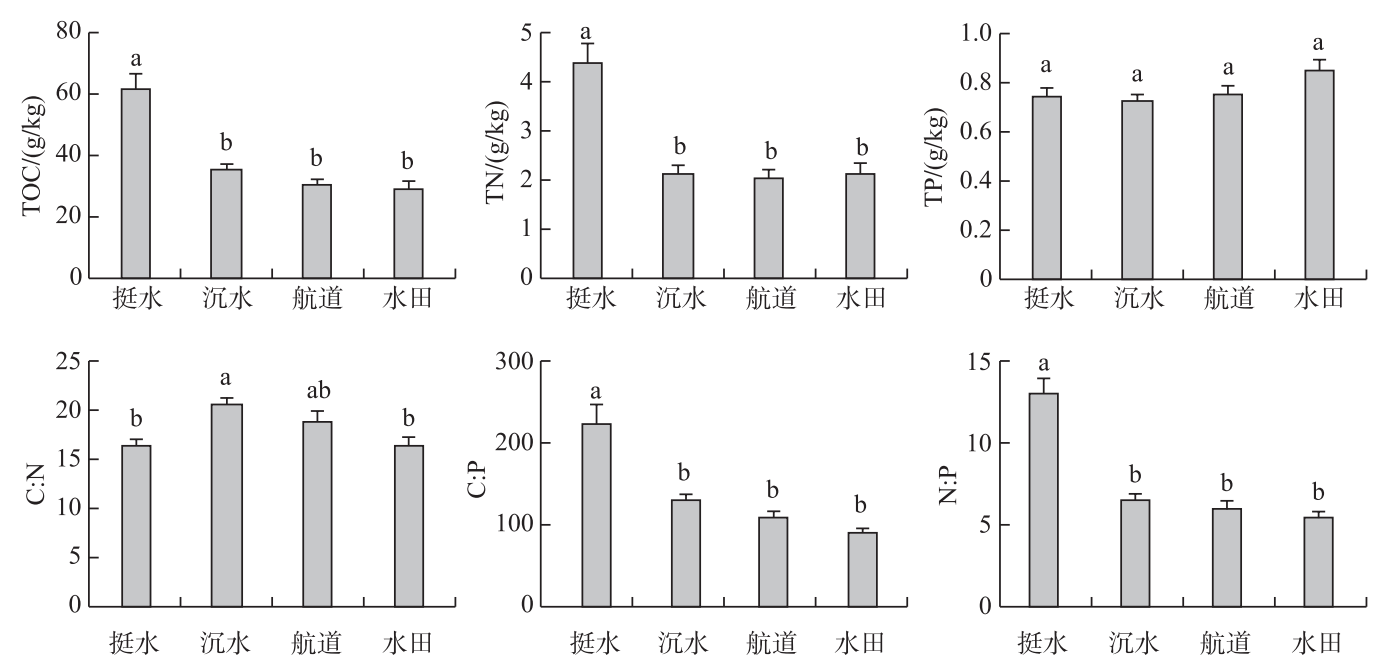

图 3 白洋淀不同植物群落区表层沉积物 C、N、P 化学计量特征对比

Fig.3 Comparison of $\mathrm{C}, \mathrm{N}$ and $\mathrm{P}$ stoichiometric characteristics of surface sediments in different plant communities in Lake Baiyangdian

\section{3 讨论}

\section{1 白洋淀表层沉积物 C、N、P 化学计量特征与我国土壤平均水平对比}

白洋淀表层沉积物 $\mathrm{C}: \mathrm{N} 、 \mathrm{C}: \mathrm{P}$ 和 $\mathrm{N}: \mathrm{P}$ 比值分别为 $18.73 、 141.00$ 和 $7.79, \mathrm{C}: \mathrm{N}: \mathrm{P}$ 比值近似为 $141: 8: 1$, 与 我国表层富含有机质土壤 $\mathrm{C} 、 \mathrm{~N} 、 \mathrm{P}$ 化学计量特征 ${ }^{[16]}$ 基本一致(图 4) 又略有不同: 其中 $\mathrm{C}: \mathrm{N}$ 比值高于中国表 层土壤 $\mathrm{C}: \mathrm{N}$ 比值 (14.4), $\mathrm{N}: \mathrm{P}$ 比值低于中国表层土壤 $\mathrm{N}: \mathrm{P}$ 比值 (9.3), $\mathrm{C}: \mathrm{P}$ 比值与中国表层土壤 $\mathrm{C}: \mathrm{P}$ 比值 (136.0) 相近. 对比表明, 与全国表层土壤相比, 白洋淀表层沉积物具有富 C、P 而少 $N$ 的特点, 当然, 此处 $N$ 元素少是相对于 C、P 元素而言.

与中国湿地土壤 $\mathrm{C} 、 \mathrm{~N} 、 \mathrm{P}$ 化学计量特征 ${ }^{[17]}$ 相比, 白洋淀表层沉积物 $\mathrm{C}: \mathrm{N}$ 比值与中国湿地土壤 $\mathrm{C}: \mathrm{N}$ 比值 (18.22) 基本一致,但 $\mathrm{C}: \mathrm{P}$ 和 $\mathrm{N}: \mathrm{P}$ 比值均小于中国湿地土壤 $\mathrm{C}: \mathrm{P}$ 比值 (245.22) 和 $\mathrm{N}: \mathrm{P}$ 比值 (13.60), 仅为全 国湿地 $C: P$ 比值和 $N: P$ 比值的 $57 \%$. 表明与全国湿地土壤相比, 白洋淀表层沉积物具有富 $P$ 而少 $C 、 N$ 的特 点. 考虑到白洋淀表层沉积物 $C 、 N 、 P$ 含量均高于我国东部大多数湖泊的现实, 化学计量特征对比表明, 相 比国内其他湿地,白洋淀 P 元素富集更为严重,具有更高的污染风险.

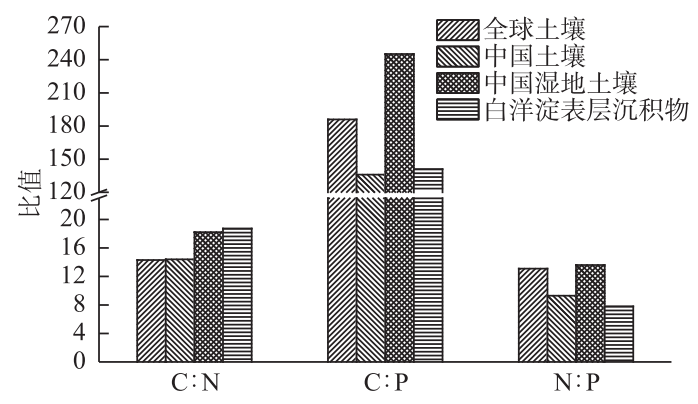

图 4 白洋淀表层沉积物 $\mathrm{C}: \mathrm{N}: \mathrm{P}$ 化学计量特征与全球及中国土壤比较 ${ }^{[15-17]}$

Fig.4 Comparison of $\mathrm{C}: \mathrm{N}: \mathrm{P}$ stoichiometry characteristics of surface sediments in Lake Baiyangdian with global and Chinese soils ${ }^{[15-17]}$ 
以上统计分析表明, 白洋淀表层沉积物 $\mathrm{C}: \mathrm{N}: \mathrm{P}$ 比例基本符合中国表层土壤 $\mathrm{C} 、 \mathrm{~N} 、 \mathrm{P}$ 化学计量特征, 总体 具有富 $\mathrm{P}$ 少 $\mathrm{N}$ 的特征, $\mathrm{P}$ 元素污染风险更大. 白洋淀表层沉积物 TN 与 TOC、TP 在 0.01 水平 (双侧) 上显著 相关, 而 TOC 与 $\mathrm{TP}$ 二者之间不相关, 又考虑 $\mathrm{C}: \mathrm{N} 、 \mathrm{C}: \mathrm{P}$ 和 $\mathrm{N}: \mathrm{P}$ 三者变异系数差异, 认为白洋淀表层沉积物 $C: N$ 具有相对稳定的比值, 而 $C: P$ 和 $N: P$ 比值不稳定,空间分异性较大.

\section{2 不同植被群落区表层沉积物 C、N、P 化学计量特征差异原因分析}

通过对比发现, 不同水生植物群落区表层沉积物 C、N、P 化学计量特征存在差异, 挺水植物区和沉水植 物区 $\mathrm{C}: \mathrm{N}: \mathrm{P}$ 比值分别近似为 $222: 13: 1$ 和 $129: 6.5: 1$, 表明表层沉积物 $\mathrm{C} 、 \mathrm{~N} 、 \mathrm{P}$ 化学计量特征与植被类型有关. 根据不同分区表层沉积物调查测试数据及前人白洋淀水生植物 C、N、P 组成的研究成果, 分析不同植被类型 区表层沉积物 $C 、 N 、 P$ 化学计量特征存在差异的原因.

首先从不同植物群落 C、N、P 含量来看. 芦苇是白洋淀挺水植物的典型代表, 暂以芦苇群落生物量及 $N$ 、 $\mathrm{P}$ 含量代替白洋淀挺水植物群落生物量及 N、P 含量. 刘存歧等 2012 年研究成果 ${ }^{[24]}$ 显示, 白洋淀挺水植物优 势物种芦苇在 8 月份生长旺盛期生物量为 $7.2 \mathrm{~kg} / \mathrm{m}^{2}$, 植物体 $\mathrm{N} 、 \mathrm{P}$ 含量分别为 9.31 和 $0.69 \mathrm{~g} / \mathrm{kg}$, 则单位面积 芦苇群落 $N 、 P$ 含量分别为 67.02 和 $4.97 \mathrm{~g} / \mathrm{m}^{2}$. 王亚琼等 2017 年调查结果 ${ }^{[25]}$ 显示, 白洋淀沉水植物 $N 、 P$ 平 均含量分别为 23.81 和 $4.59 \mathrm{~g} / \mathrm{kg}$, 均高于芦苇. 然而, 白洋淀沉水植物群落生物量远低于芦苇群落 ${ }^{[26]}$, 生物 量最高的篦齿眼子菜群落为 $1.22 \mathrm{~kg} / \mathrm{m}^{2}$, 仅为芦苇群落生物量的 $1 / 6$. 暂以篦齿眼子菜生物量作为白洋淀沉 水植物群落的生物量, 则单位面积沉水植物群落最大 $\mathrm{N} 、 \mathrm{P}$ 含量分别为 29.05 和 $5.60 \mathrm{~g} / \mathrm{m}^{2}$. C 是生物体干物 质的主要成分, 夏成星研究显示 ${ }^{[27]}$, 我国东部内陆水域挺水植物 C 含量为 $392.29 \mathrm{~g} / \mathrm{kg}$, 沉水植物的 C 含量 为 $336.64 \mathrm{~g} / \mathrm{kg}$, 以此作为白洋淀芦苇群落和沉水植物群落的 C 含量. 则白洋淀单位面积芦苇群落和沉水植 物群 $\mathrm{C}$ 含量分别为 2824.49 和 $410.7 \mathrm{~g} / \mathrm{m}^{2}$. 根据以上计算结果, 白洋淀单位面积挺水植物群落生物体 $\mathrm{C} 、 \mathrm{~N}$ 含 量分别是沉水植物群落的 6.88 倍和 2.31 倍, 而 P 含量基本相同 (图 5a), C、N、P 元素含量相对大小与相应 区域表层沉积物的 $C 、 N 、 P$ 含量 (图 $5 b$ ) 具有一致性.
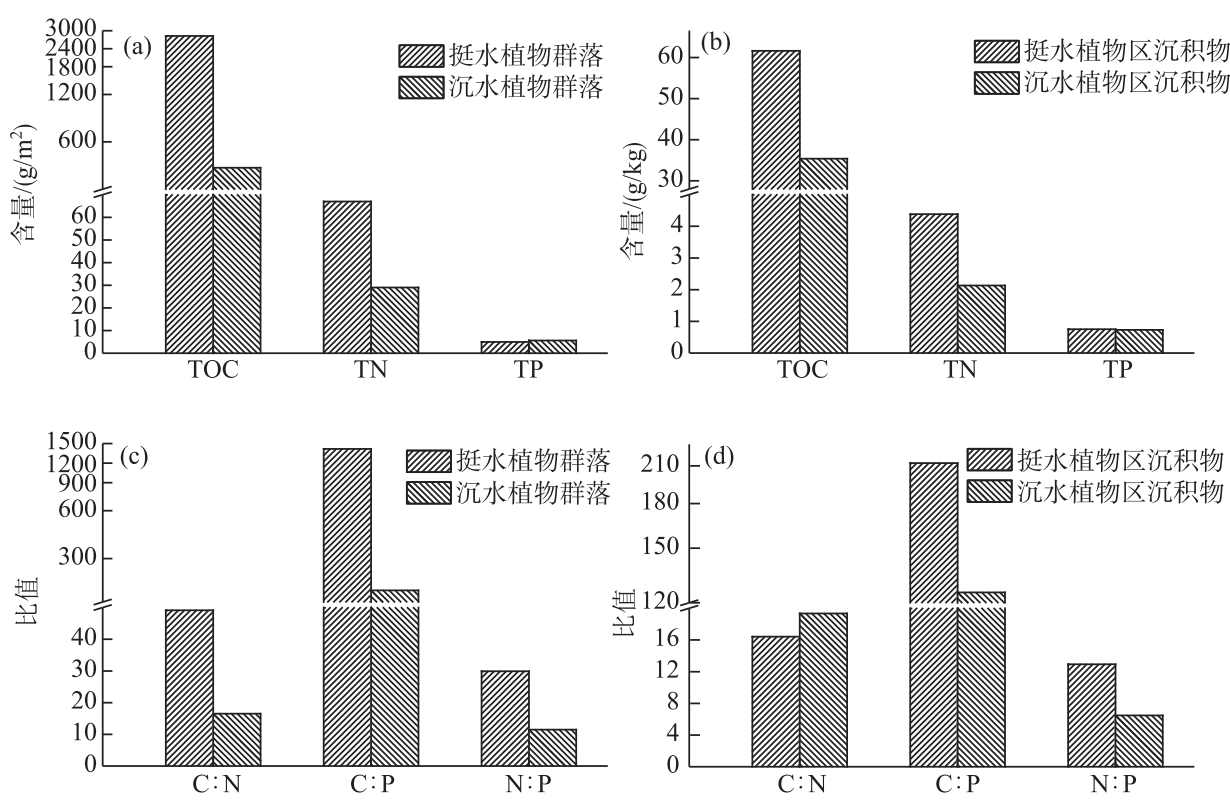

图 5 不同植物群落与相应分区表层沉积物 $\mathrm{C} 、 \mathrm{~N} 、 \mathrm{P}$ 含量和化学计量特征对比

Fig.5 Comparison of $\mathrm{C}, \mathrm{N}$ and $\mathrm{P}$ contents and stoichiometric characteristics of different plant communities and the surface sediments of corresponding regions

从不同植物群落 $\mathrm{C} 、 \mathrm{~N} 、 \mathrm{P}$ 比值来看 (图 5c), 以芦苇为代表的挺水植物 $\mathrm{C}: \mathrm{N}(49.16) 、 \mathrm{C}: \mathrm{P}(1468.72$ ) 和 $\mathrm{N}: \mathrm{P}(29.88)$ 比值均高于沉水植物 (分别为 $16.50 、 189.47$ 和 11.49). 各分区表层沉积物 $C 、 N 、 P$ 比值对比显示 
(图 5d), 挺水植物区表层沉积物 $\mathrm{C}: \mathrm{P}$ 和 $\mathrm{N}: \mathrm{P}$ 比值均大于沉水植物区表层沉积物, 与植物群落一致; 而挺水 植物区表层沉积物 $\mathrm{C}: \mathrm{N}$ 比值却小于沉水植物区沉积物 $\mathrm{C}: \mathrm{N}$ 比值, 与挺水植物沉水植物 $\mathrm{C}: \mathrm{N}$ 比值大小关系 不同. 前人通过实验对比发现, 植物分解速率与 $\mathrm{C}: \mathrm{N}$ 比值、 $\mathrm{C}: \mathrm{P}$ 比值、木质素呈显著负相关 ${ }^{[40]}$. 沉水植物 $\mathrm{C}: \mathrm{N}$ 比值、 $\mathrm{C}: \mathrm{P}$ 比值均低于挺水植物, 故沉水植物凋亡后分解速率大于挺水植物. 王傅研究发现 ${ }^{[41]}$, 沉水植 物分解后部分 $\mathrm{N}$ 元素以气体形式溢出水体, 而 $\mathrm{C} 、 \mathrm{P}$ 大部分进人到底泥中. 因此, 植物调亡后枯落物分解速率 的差异导致沉水植物区表层沉积物 $\mathrm{C}: \mathrm{N}$ 比值大于挺水植物区沉积物 $\mathrm{C}: \mathrm{N}$ 比值.

航道区植物群落类型与沉水植物区相同, 二者表层沉积物 C、N、P 化学计量特征有一定相似性. 但航道 区沉积物 TOC 和 TN 含量略低于沉水植物区, TP 含量略高于沉水植物区, C : N 比值介于沉水植物区和挺水 植物区之间, 表明航道较强的水动力条件对物质沉积过程产生了一定影响. 对于水田区, 由于农作物定期收 割外运, 枯落物较少, 导致表层沉积物 TOC 平均含量最低; 而沉积物中 TP 含量高于其他各分区, 推测是受水 田区农业施肥影响.

由此表明, 白洋淀植被枯落物是表层沉积物 C、N、P 的主要来源, 挺水植物区和沉水植物区表层沉积物 $C 、 N 、 P$ 化学计量特征受植物群落生物量、 $\mathrm{C} 、 \mathrm{~N} 、 \mathrm{P}$ 化学计量特征以及枯落物分解速率等多个因素影响. 航道 区和水田区人类活动较强, 表层沉积物 $\mathrm{C} 、 \mathrm{~N} 、 \mathrm{P}$ 化学计量特征除受植物类型影响外, 还受农业施肥、作物收割 等人类活动影响.

\section{4 结论}

1) 白洋淀表层沉积物 TOC、TN、TP 含量均值分别为 $39.64 、 2.62$ 和 $0.75 \mathrm{~g} / \mathrm{kg}$, 均高于 1995 年沉积物相应 组分含量,在我国东部主要湖泊中处于较高水平.

2) 白洋淀表层沉积物 $\mathrm{C}: \mathrm{N}: \mathrm{P}$ 比值与中国表层土壤相近, 平均值为 $141: 8: 1, \mathrm{C}: \mathrm{N}$ 比值相对稳定, C:P 和 $\mathrm{N}: \mathrm{P}$ 比值空间分异性较大. 不同植物群落区表层沉积物 $\mathrm{C} 、 \mathrm{~N} 、 \mathrm{P}$ 化学计量特征存在显著差异, 挺水植物区和 沉水植物区表层沉积物 $\mathrm{C}: \mathrm{N}: \mathrm{P}$ 比分别为 $222: 13: 1$ 和 $129: 6.5: 1$.

3 ) 白洋淀表层沉积物 $\mathrm{C} 、 \mathrm{~N} 、 \mathrm{P}$ 化学计量特征受植物群落生物量、磷氮磷化学计量特征、枯落物分解速率 以及人类活动等多个因素影响. 建议在水生植物生长末期收割打捞运出淀外, 减少淀内 N、P 营养盐累积, 减 缓白洋淀富营养化和沼泽化进程.

\section{5 参考文献}

[ 1 ] Yi YJ, Lin CQ, Tang CH. Hydrology, environment and ecological evolution of Lake Baiyangdian since 1960s. J Lake Sci, 2020, 32(5)：1333-1347. DOI: 10.18307/2020.0500. [易雨君, 林楚翘, 唐彩红. 1960s 以来白洋淀水文、环境、生 态演变趋势. 湖泊科学, 2020, 32(5): 1333-1347.]

[ 2 ] Cao TG, Yi YJ, Liu HX et al. Integrated ecosystem services-based calculation of ecological water demand for a macrophyte-dominated shallow lake. Global Ecology and Conservation, 2020, 21 : e00858. DOI: 10.1016/j.gecco.2019.e00858.

[ 3 ] Tang CH, Yi YJ, Yang ZF et al. Effects of ecological flow release patterns on water quality and ecological restoration of a large shallow lake. Journal of Cleaner Production, 2018, 174: 577-590. DOI: 10.1016/j.jclepro.2017.10.338.

[4] Wang SR ed. Sediment-water interface process of lakes. Beijng: Science Press, 2014. [王圣瑞. 湖泊沉积物-水界面过 程. 北京: 科学出版社, 2014.]

[ 5 ] Shen J. Progress and prospect of palaeolimnology research in China. J Lake Sci, 2009, 21(3) : 307-313. DOI: 10.18307/ 2009.0301. [沈吉. 湖泊沉积研究的历史进展与展望. 湖泊科学, 2009, 21(3) : 307-313.]

[ 6 ] Algesten G, Sobek S, Bergström AK et al. Role of lakes for organic carbon cycling in the boreal zone. Global Change Biol$o g y, 2004,10$ (1) : 141-147. DOI: 10.1111/j.1365-2486.2003.00721.x.

[ 7 ] Zhang L, Fan CX, Wang JJ et al. Nitrogen and phosphorus forms and release risks of lake sediments from the middle and lower reaches of the Yangtze River. J Lake Sci, 2008, 20(3) : 263-270. DOI: 10.18307/2008.0301. [张路, 范成新, 王 建军等. 长江中下游湖泊沉积物氮磷形态与释放风险关系. 湖泊科学, 2008, 20(3) : 263-270.]

[ 8 ] Stackpoole SM, Butman DE, Clow DW et al. Inland waters and their role in the carbon cycle of Alaska. Ecological Applications, 2017, 27(5) : 1403-1420. DOI: 10.1002/eap.1552.

[ 9 ] Tang F. Study on the stoichiometric characteristics of carbon, nitrogen and phosphorus in lake sediments and their respon- 
ses to organic matter from different sources[Dissertation]. Nanjing: Nanjing Normal University, 2020. [ 唐芳. 湖泊沉积物 碳氮磷计量化学特征及其对不同来源有机质的响应研究 [学位论文]. 南京: 南京师范大学, 2020.]

[10] Cheng B, Zhao YJ, Zhang WG et al. The research advances and prospect of ecological stoichiometry. Acta Ecologica Sini$c a, 2010,30(6): 1628-1637$. [程滨, 赵永军, 张文广等. 生态化学计量学研究进展. 生态学报, 2010, 30(6): 1628-1637.]

[11] Lu TP, Shi ZT, Niu J et al. Research progresses and prospects of terrestrial ecological stoichiometry in China. Soils, 2016, 48(1) : 29-35. [ 卢同平, 史正涛, 牛洁等. 我国陆生生态化学计量学应用研究进展与展望. 土壤, 2016, 48(1): 29-35.]

[12] Sterner RW, Elser JJ, Vitousek P eds. Ecological stoichiometry: The biology of elements from molecules to the biosphere. Princeton University Press: 2017.

[13] Güsewell S. N :P ratios in terrestrial plants: Variation and functional significance. New Phytologist, 2004, 164(2) : 243266. DOI: $10.1111 /$ j.1469-8137.2004.01192.x.

[14] He JS, Han XG. Ecological stoichiometry: Searching for unifying principles from individuals to ecosystems. Chinese Journal of Plant Ecology, 2010, 34(1) : 2-6. [ 贺金生, 韩兴国. 生态化学计量学: 探索从个体到生态系统的统一化理论. 植 物生态学报, 2010, 34(1) : 2-6.]

[15] Cleveland CC, Liptzin D. C: N: P stoichiometry in soil: Is there a "Redfield ratio" for the microbial biomass? Biogeochemistry, 2007, 85(3) : 235-252. DOI: 10.1007/s10533-007-9132-0.

[16] Tian HQ, Chen GS, Zhang C et al. Pattern and variation of $\mathrm{C}: \mathrm{N}$ ratios in China's soils: A synthesis of observational data. Biogeochemistry, 2010, 98(1/2/3) : 139-151. DOI: 10.1007/s10533-009-9382-0.

[17] Zhang ZS, Lv XG, Xue ZS et al. Is there a redfield-type C:N:P ratio in Chinese wetland soils? Acta Pedologica Sinica, 2016, 53(5) : 1160-1169. [张仲胜, 吕宪国, 薛振山等. 中国湿地土壤碳氮磷生态化学计量学特征研究. 土壤学 报, 2016, 53(5): 1160-1169.]

[18] Hu C, Li F, Xie YH et al. Soil carbon, nitrogen, and phosphorus stoichiometry of three dominant plant communities distributed along a small-scale elevation gradient in the East Dongting Lake. Physics and Chemistry of the Earth, Parts A/B/ $C$, 2018, 103: 28-34. DOI: 10.1016/j.pce.2017.04.001.

[19] Zhang ZS, Lu XG, Song XL et al. Soil C, N and P stoichiometry of Deyeuxia angustifolia and Carex lasiocarpa wetlands in Sanjiang Plain, Northeast China. Journal of Soils and Sediments, 2012, 12(9) : 1309-1315. DOI: 10.1007/s11368-0120551-8.

[20] Du YH, Liu C, Chen KN et al. Occurrence and internal loadings of nitrogen and phosphorus in the sediment of Lake Baiyangdian. J Lake Sci, 2018, 30(6) : 1537-1551. DOI : 10.18307/2018.0606. [杜奕衡, 刘成, 陈开宁等. 白洋淀沉积物 氮磷赋存特征及其内源负荷. 湖泊科学, 2018, 30(6): 1537-1551.]

[21] Li ZX, Sun Y, Zhang YR et al. Occurrence and distribution characteristics of nitrogen in sediments of Lake Baiyangdian during the icebound period. Environmental Engineering, 2019, 37 (12) : 29-33. DOI: 10.13205/j.hjgc.201912006. [李再. 兴, 孙悦, 张艺由等. 白洋淀冰封期沉积物中氮赋存形态及分布特征. 环境工程, 2019, 37(12) : 29-33.]

[22] Wang JZ, Liu Z, Wei H et al. Spatial characteristics, risk assessment, and source analysis of elements in surface sediments from the Lake Baiyangdian. Environmental Science, 2020, 41(1) : 224-231. DOI: 10.13227/j.hjkx. 201907005. [汪敬忠, 刘卓, 魏浩等. 白洋淀表层沉积物元素的空间特征、风险评价及来源分析. 环境科学, 2020, 41 (1): 224-231.]

[23] Li CY, Cheng L, Wang TF et al. Nitrogen and phosphorus diffusive fluxes across the sediment-water interface before and after dredging typical areas of Lake Baiyangdian. Acta Scientiae Circumstantiae, 2021, 41 (4) : 1401-1409. DOI: 10. 13671/j.hjkxxb.2020.0331. [李成瑶, 程立, 王同飞等. 白洋淀典型区域清淤前后沉积物的氮磷扩散通量研究. 环境 科学学报, 2021, 41(4): 1401-1409.]

[24] Liu CQ, Li A, Li B et al. Dynamics of biomass, nitrogen and phosphorus storage of Phragmites australis in Lake Baiyangdian. Acta Scientiae Circumstantiae, 2012, 32(6) : 1503-1511. DOI: 10.13671/j.hjkxxb.2012.06.009. [刘存歧, 李昂, 李博等. 白洋淀湿地芦苇生物量及氮、磷储量动态特征. 环境科学学报, 2012, 32(6): 1503-1511.]

[25] Wang YQ, Xue PY, Geng LP et al. Distribution characteristics of nitrogen and phosphorus in sediments-submerged macrophytes-water systems of Lake Baiyangdian. Journal of Soil and Water Conservation, 2017, 31(3) : 304-309. [王亚琼, 薛 培英, 耿丽平等. 白洋淀沉积物-沉水植物-水系统氮、磷分布特征. 水土保持学报, 2017, 31(3): 304-309.]

[26] Li F, Xie YH, Yang G et al. Preliminary survey on aquatic vegetations in Lake Baiyangdian. Chinese Journal of Applied E- 
cology, 2008, 19(7) : 1597-1603. [李峰, 谢永宏, 杨刚等. 白洋淀水生植被初步调查. 应用生态学报, 2008,19 (7) : 1597-1603.]

[27] Xia CX. Study on ecological stoichiometry of aquatic plants in the inland waters in eastern China[Dissertation]. Wuhan: Wuhan University, 2014. [夏成星. 中国东部内陆水域水生植物生态化学计量学研究 [学位论文]. 武汉: 武汉大 学, 2014.]

[28] Gao JJ ed. Anxin County Annals. Beijing: Xinhua Publishing House, 2000: 118-119. [高俊杰. 安新县志. 北京: 新华出 版社, 2000: 118-119.]

[29] Zhang MM, Wu XQ. Changes in hydrological connectivity and spatial morphology of Baiyangdian wetland over the last 20 years. Acta Ecologica Sinica, 2018, 38(12) : 4205-4213. [张梦嫚, 吴秀芹. 近 20 年白洋淀湿地水文连通性及空间形 态演变. 生态学报, 2018, 38(12): 4205-4213.]

[30] Gu T, Wang DM, Yang M et al. Determination of total organic carbon in soil and sediment by high frequency infrared carbon sulfur analyzer. Geology and Mineral Resources of South China, 2015, 31(3): 306-310. [ 顾涛, 王迪民, 杨梅等. 高 频红外碳硫仪测定土壤/沉积物中总有机碳研究. 华南地质与矿产, 2015, 31(3): 306-310.]

[31] Xie XL, Li HF, Li XY et al. Comparative analysis of semi-micro nitrogen determination method and automatic nitrogen determination method for soil total nitrogen. Ecology and Environment Sciences, 2012, 21(6): 1071-1074. [谢小玲, 李海 锋, 李雪荣等. 土壤全氮半微量定氮法与自动定氮仪定氮法的比较分析. 生态环境学报, 2012, 21 (6): 1071-1074.]

[32] Peng H, Zhang DY, Jiang O et al. Determination of total phosphorus in the soil with highly organic components by X-ray fluorescence filter paper chromatographic method. Phosphate \& Compound Fertilizer, 2009, 24(3): 66-67. [彭桦, 张东 云, 姜鸥等. $X$ 射线苂光光谱滤纸片法测定有机成分高的土壤中的总磷. 磷肥与复肥, 2009, 24(3): 66-67.]

[33] Zhang GF, Yu SF, Dong ZM et al. The current status of Baiyangdian sediment and its influence on water eutrophication. Enviromental Science, 1995, 16(S1) :24-27. [张国峰, 于世繁, 董志民等. 白洋淀底质现状及对水体富营养化的影 响. 环境科学, $1995,16(\mathrm{~S} 1): 24-27$.

[34] Zhang JW, Wei J, Liu L et al. Distribution characteristics and pollution assessment of nutrients in Hengshui lake sediments. Environmental Science, 2020, 41(12) : 5389-5399. DOI: 10.13227/j.hjkx.202004237. [张嘉雯, 魏健, 刘利等. 衡水湖沉积物营养盐形态分布特征及污染评价. 环境科学, 2020, 41(12) : 5389-5399.]

[35] Yu H, Zhang WB, Lu SY et al. Spatial distribution characteristics of surface sediments nutrients in lake Hongze and their pollution status evaluation. Environmental Science, 2010, 31(4) : 961-968. DOI: 10.13227/j.hjkx.2010.04.003. [余辉, 张文斌, 卢少勇等. 洪泽湖表层底质营养盐的形态分布特征与评价. 环境科学, 2010, 31(4) : 961-968.]

[36] Yang Y, Liu QG, Hu ZJ et al. Spatial distribution of sediment carbon, nitrogen and phosphorus and pollution evaluation of sediment in Taihu Lake Basin. Acta Scientiae Circumstantiae, 2014, 34(12) : 3057-3064. DOI: 10.13671/j.hjkxxb.2014. 0710. [杨洋, 刘其根, 胡忠军等. 太湖流域沉积物碳氮磷分布与污染评价. 环境科学学报, 2014, 34 (12): 3057-3064. ]

[37] Wang SR, Ni D, Jiao LX et al. Space-time variety of organic matter and nutrient in surface sediments from Poyang lake. Journal of Environmental Engineering Technology, 2012, 2(1):23-28. [王圣瑞, 倪栋, 焦立新等. 鄱阳湖表层沉积物 有机质和营养盐分布特征. 环境工程技术学报, 2012, 2(1): 23-28.]

[38] Liu J. Characteristics and evaluation of nutrient and heavy metal pollution in sediments from Dongting Lake[Dissertation]. Xiangtan: Xiangtan University, 2019. [刘俊. 洞庭湖沉积物营养盐和重金属污染特征及评价研究 [ 学位论文]. 湘 潭: 湘潭大学, 2019.]

[39] Su HJ, Wu Y, Xia WL et al. Community level stoichiometric characteristics of submerged macrophytes and their influencing factors in the mid-lower Yangtze lakes. J Lake Sci, 2017, 29(2) : 430-438. DOI: 10.18307/2017.0219. [苏豪杰, 吴耀, 夏午来等. 长江中下游湖泊群落水平下沉水植物碳、氮、磷化学计量特征及其影响因素. 湖泊科学, 2017, 29(2) : 430-438.]

[40] Chimney MJ, Pietro KC. Decomposition of macrophyte litter in a subtropical constructed wetland in south Florida (USA). Ecological Engineering, 2006, 27(4) : 301-321. DOI: 10.1016/j.ecoleng.2006.05.016.

[41] Wang F. Submerged plant decomposition process and migration and transformation of water and sediment carbon, nitrogen, phosphorus[Dissertation]. Beijing: Beijing Normal University, 2012.[王傅. 沉水植物分解过程及碳, 氮, 磷在水-底 泥的迁移转化 [学位论文]. 北京: 北京师范大学, 2012.] 